\title{
The Cartography of Syntactic Structures
}

\author{
GUGLIELMO CINQUE \\ University of Venice \\ cinque@unive.it \\ LUIGI RIZZI \\ University of Siena \\ rizzil@unisi.it
}

\section{Introduction}

Syntactic structures are complex objects, whose subtle properties have been highlighted and elucidated by half a century of formal syntactic studies, building on a much older tradition. Structures are interesting objects of their own, both in their internal constitution and in their interactions with various grammatical principles and processes. The cartography of syntactic structures is the line of research which addresses this topic: it is the attempt to draw maps as precise and detailed as possible of syntactic configurations. Broadly construed in this way, cartography is not an approach or a hypothesis: it is a research topic asking the question: what are the right structural maps for natural language syntax? Answers may differ, and very different maps may be, and have been, proposed, but the question as such inevitably arises as a legitimate and central question for syntactic theory. If it is a virtual truism that cartography can be construed as a topic and not as a framework, it is also the case that cartographic studies have often adopted certain methodological and heuristic guidelines, and also certain substantive hypotheses on the nature of syntactic structures, which form a coherent body of assumptions and a rather well-defined research direction; we will try to illustrate some ideas and results of this direction in the present chapter.

If structures have, in a sense, always been central in generative grammar, the idea of focusing on structural maps arose around the early nineties, following a track parallel to and interacting with the Minimalist Program. Perhaps the main triggering factor was the explosion of functional heads identified and implied in syntactic analyses in the first ten years of the Principles and Parameters framework. One critical step was the full-fledged extension of X-bar theory to the functional elements of the clause (Chomsky 1986) as a CP - IP - VP structure; and the observation that other configurations, e.g. nominal expressions, were amenable to a hierarchical structure with a lexical projection embedded within a functional structure (such as Abney's DP hypothesis, Abney 1987). These advances provided a natural format for the study of the structure of phrases and clauses as hierarchical sequences of the same building block, the fundamental X-bar schema (or, later, elementary applications of Merge); the lowest occurrence of the building block typically is the projection of a lexical category, e.g. a noun or a verb, and this element is typically completed by a series of 
building blocks headed by functional elements, providing more abstract semantic specifications to the descriptive content of the lexical head: tense, mood, aspect for the verb, definiteness, specificity, number for the noun, etc.

If the first step was the idea that clauses and phrases are formed by a lexical structure and a higher functional structure, both corresponding to elementary building blocks hierarchically organized, the second crucial step was the observation that the functional structure typically consists of more than one head. In fact, a Complementizer Phrase (CP) and an Inflectional Phrase (IP) zone were isolated from the outset, but it became clear very soon that the same kinds of evidence which supported the analysis of inflected verbs in terms of the distinction between I and V would lead to the splitting of I into more elementary components. The same logic led to a later splitting of the CP and DP zones into more articulated hierarchical sequences of functional projections.

The initial impulse for splitting the IP was provided by Pollock's seminal paper on verb movement in French and English (Pollock 1989, versions of which circulated already around the mid eighties). Pollock showed that assuming a single I position did not provide enough space to account for the different positions which can be occupied by different morphological forms of the verb in French: infinitival verbs may remain in the VP, as in (1)a, or be moved to a higher position across lower adverbs like complètement (completely), as in (1)b; finite verbs move to an even higher position across negative pas, as in (1)c:
(1) a. ne $X_{1}$ pas $X_{2}$ complètement [X3 comprendre] la théorie ... neg not completely understand the theory
$\mathrm{b}$ ne $\mathrm{X}_{1}$ pas $[\mathrm{X} 2$ comprendre $]$ complètement $\mathrm{X}_{3}$ la théorie ...
c Il ne [X1 comprend] pas $\mathrm{X}_{2}$ complètement $\mathrm{X}_{3}$ la théorie

If I splits into at least two heads $\mathrm{X}_{1}$ and $\mathrm{X}_{2}$, Pollock argued, the three positions of (1) can be naturally accommodated by assuming optional movement of the infinitival verb from its VP-internal position $\mathrm{X}_{3}$ to $\mathrm{X}_{2}$, and obligatory verb movement of the finite verb to $X_{1}$. This analysis, also building on Emonds (1978), introduced a fundamental insight: adverbs basically don't move, except in the cases in which they are displaced for scope-discourse reasons, focalized, and the like; variations within a language and across languages of verb-adverb orders are due to verb movement in the inflectional space, a particular instance of head movement. This approach in fact united two lines of research which have become integral components of the cartographic studies: on the one hand, the analysis of the word order properties of verbs with respect to adverbial and arguments in terms of head movement, as mentioned; on the other hand, the idea that inflectional morphology is done in the syntax and is the result of movement rules involving roots and affixes, an idea going back to the analysis of verb affixation in English in Syntactic Structures (Chomsky 1957). The Emonds-Pollock approach united the two trends by proposing that the verb could be attracted to different functional positions to pick up affixes and get properly inflected, thus changing its position with respect to adverbs and other elements, which made it possible to capture many important form-position correlations. 
The question then arose of the proper labeling of $X_{1}$ and $X_{2}$. Belletti's (1990) proposal was that the higher functional projection of the clause is the one responsible for subject-verb agreement (AgrS in the traditional terminology), and the lower one expresses tense. This order AgrS - T is immediately reflected in the order of prefixes or particles in e.g., the Bantu languages; while in languages in which these properties are expressed by suffixes, i.e. the Romance languages, the order is the mirror image (see Italian parl-av-ano, root-T-AgrS, "(they) spoke"), as is to be expected under Baker's (1988) Mirror Principle: the verb moves to pick up the closest suffix, which therefore appears as the one immediately attached to the root, etc.).

The logic of this argumentation, combining the syntactic make-up of inflectional morphology via head-movement and the study of the order of arguments and adjuncts with respect to different verbal forms, quickly led to a finer splitting of the inflectional space into a sequence of functional heads expressing properties of mood and modality, tense, aspect, voice. For a few years, around the late eighties, this methodology led to the discovery and postulation of a variety of functional heads driven by the analytic necessities of particular morphosyntactic problems, a trend which sometimes gave the impression that the process would lead to an ever increasing complexity of the syntactic representations. How rich could be the "right" functional structure of clauses and phrases? One of the driving ideas of the cartographic projects was precisely to complement this trend of bottom-up, problem-related discovery with a more topdown, global perspective, trying to make a rough estimate of the upper limit of the structural complexity. Instrumental to this endeavor was the working assumption that each morphosyntactic feature would correspond to an independent syntactic head with a specific slot in the functional hierarchy (cf. also Kayne 2005a,15). Much of the cartographic work has consisted in the attempt, in various forms, to use this working hypothesis as a heuristic guideline, thus spelling out empirical arguments supporting or disconfirming its validity across languages.

\section{Methodology and evidence}

In the first half of last century, in part as a reaction to what was then felt as an unwarranted application of European grammatical categories and constructions to non-European languages, the common wisdom in American structuralism (epitomized in Joos 1957,96) was that "languages could differ from each other without limit and in unpredictable ways" so that each language should be studied "without any preexistent scheme of what a language must be". The rejection of these assumptions, which are still adopted today by many functionalists ${ }^{1}$, was implicit throughout the history of generative grammar ${ }^{2}$, and is made explicit in Chomsky's (2001, ) "Uniformity Principle" ("In the absence of compelling evidence to the contrary, assume languages to be uniform, with variety restricted to easily detectable properties of utterances."). The cartographic approach follows this idea in assuming that all languages share the

\footnotetext{
${ }^{1}$ See for example LaPolla and Poa (2002,2): "Each language is a unique set of language-specific conventions, and so each language should be described in its own terms", or Haspelmath (2007, ) "descriptive linguists still have no choice but to adopt the Boasian approach of positing special language particular categories for each language. Theorists often resist it, but the crosslinguistic evidence is not converging on a smallish set of possibly innate categories. On the contrary, almost every newly described language presents us with some "crazy" new category that hardly fits existing taxonomies."

${ }^{2}$ See, for example, Koopman and Sportiche (1991,218f): "[W]e suppose that the null assumption concerning language variation is that it does not exist."
} 
same principles of phrase and clause composition and the same functional make-up of the clause and its phrases. ${ }^{3}$

More precisely the cartographic approach assumes, as the evidence of the last several years seems to indicate, that the distinct hierarchies of functional projections dominating VP, NP, AP, PP, IP, etc., may be universal in the type of heads and specifiers that they involve, in their number, and in their relative order, even if languages differ in the type of movements that they admit or in the extent to which they overtly realize each head and specifier (Rizzi 1997; Cinque 1999; 2002,3f).

This is the strongest position one could take; one which implies that if some language provides evidence for the existence of a particular functional head (and projection), then that head (and projection) must be present in every other language, whether the language offers overt evidence for it or not (cf. Kayne 2005,12; Cinque 2006a,4). ${ }^{4}$

A weaker position would consist in assuming that languages may differ in the type or number of functional projections they select from a universal inventory, or in their order. $^{5}$

Although the choice between these two positions will ultimately be decided by the nature of things, methodologically it would be wrong, it seems, to adopt the weaker position as a first working hypothesis. That would only make us less demanding with respect to the facts and could lead us to miss more subtle evidence supporting the stronger position, a risk not present under the other option (Cinque 2002,4).

The question whether such universal hierarchies of functional projections are primitive objects of UG, or can be derived from interface or more general external conditions is important, but fundamentally orthogonal to the prior task of drawing their precise map, and perhaps not easily determinable at the present state of our knowledge.

The evidence brought to bear in the literature on the mapping of universal hierarchies of functional projections comes from a variety of sources.

An early source for postulating (abstract) functional projections was the existence of certain systematic word order differences among languages, like Pollock's (1989) classical argument for positing a non-lexical head higher than VP and lower than I (or T), to which finite verbs raise in French (but not in English), along the lines discussed in the introductory section.

Another important source of evidence is the relative order of the functional morphemes overtly realized in the languages of the world (to the extent that one can establish reasonable correspondences among the functional morphemes of different languages). Though languages differ as to what functional categories they overtly realize, the partial orders displayed by different languages seem to fit in a unique

\footnotetext{
${ }^{3}$ This is not to say that it is always easy to establish precise correspondences between the functional categories overtly displayed by different languages. Caution must be exercised, but there is no a priori reason to rule out the possibility that such correspondences can ultimately be established. In fact, this has turned out to be possible in a number of cases through in-depth investigation. See, for example, the case of French peu and English bit (rather than little) discussed in Kayne (2005, §4.2).

${ }^{4}$ The literature offers a number of cases supporting this general hypothesis. See, for example, the discovery of more subtle evidence for the presence of a DP projection in languages like Serbo-Croatian, Russian, and Japanese, which lack overt determiners (Progovac 1998, Pereltsvaig 2007, Furuya 2008); or the indirect evidence discussed in Kayne $(2003,219)$ and Cinque $(2006 \mathrm{~b})$ for the presence of numeral classifiers in languages like English and Italian, which are traditionally taken not to be numeral classifier languages.

${ }^{5}$ This is the position taken, for example, by Thráinsson (1996) and Bobaljik and Thráinsson (1998), among others. See also Fukui (1995).
} 
macro-hierarchy despite occasional inconsistencies, which have proved (and hopefully will prove, as our knowledge progresses) solvable.

Preliminary inquiries on the functional hierarchies of the left periphery of the clause (Rizzi 1997, 2001, 2004a,b; Benincà 2001,2006, Benincà and Poletto 2004; Bocci 2004; Benincà and Munaro to appear; Cruschina 2006; Frascarelli and Hinterhölzl. 2007, Frascarelli and Puglielli to appear, among others), of the core functional structure of the clause (Cinque 1999, 2006; Shlonsky 1997, 2000; Sigurðsson 2000; Cardinaletti 2004; Schweikert 2005; Bianchi 2006; and, for its relevance for computational linguistics, Chesi 2005), of the DP (Cinque 1994, Scott 2002, Brugè 2002, Giusti 2002, Nicolis 2008, Svenonius 2008a), and of PPs (see the contributions in Asbury, Dotlačil, Gehrke, Nouwen 2008 and Cinque and Rizzi to appear), have largely confirmed the working hypothesis that there may be a universal functional design for the clause and its major phrases holding across languages. ${ }^{6}$

Of course, to determine the relative order of functional morphemes one has to have an idea of what the classes of such elements are as opposed to the lexical ones (see section 3 below for some discussion), and this task often requires "regularizing" the orders found across languages, as they can be obscured to various degrees by various types of syntactic movements. So for example the relative order of functional morphemes that appear to the right of a certain lexical category, as suffixes or free morphemes, is most often (though by no means always) the mirror image of the same functional morphemes that appear on the left of the same lexical category in other languages, arguably a consequence of the lexical category moving across the functional morphemes in the former type of languages (see Baker 1985 for the original formulation of the Mirror Principle and, for recent discussion, see Cinque 2008).

Analogously, as noted in Carlson $(1983,73)$, one of the earliest and most enlightening discussions of functional categories in the generative tradition, the Latin coordinating enclitic conjunction -que exemplified in (2) is not interpreted as conjoining with a like constituent what precedes it ( i.e. the unit $[o b e \bar{a} s]$ ), but the entire higher unit $[o b e \bar{a} s$ $r \bar{e} s]$ (as in English). This again can be "regularized" if the movements that created (2) (from ...ob eās rēs-que) are undone.
(2) $o b$
eās-que rēs
because.of these-and things
'and because of these things'

\footnotetext{
${ }^{6}$ Some authors have argued that this particular assumption of the cartographic approach is incorrect because it rests on transitivity (if $\mathrm{A}>\mathrm{B}$ and $\mathrm{B}>\mathrm{C}$, then $\mathrm{A}>\mathrm{C}$ ), which appears to fail in certain cases (see Bobaljik 1999, Nilsen 2003, and also Zwart 2006). Caution however is in order given the otherwise general validity of transitivity, and the possibility that some account exists which renders these cases irrelevant for transivity issues. See in fact Cinque (2004,footnotes 22 and 43 for evidence to this effect). Van Craenenbroeck's (2006) analogous argument from an apparent transitivity failure in the left periphery also ignores the possibility that the complementizer may occupy more than one position, thus rendering his case irrelevant to the transitivity issue. That an element like that may appear more than once and in different positions in the left periphery of a clause is straightforwardly shown by many cases of multiple occurrences of that, e.g., in Brazilian Portuguese, Gascon and Piedmontese, structures with orders like I think that JOHN that you should meet, with the first that functioning as declarative force marker, and the second as a focus marker (see Mioto 1998, Poletto 2000,148-50 for relevant discussion).
} 
These are two out of the many cases where care must be taken to render things comparable and to expose the deeper regularities that underlie the functional make-up of the clause and its phrases.

\section{Inventory of functional categories}

A guiding idea of much current cartographic work is that the inventory of functional elements (heads or specifiers of functional projections) is much larger than is generally thought. In all grammatical traditions it is customary to make, in one way or another, some distinction between lexical categories (like Nouns and Verbs: see Baker 2003) and functional, or grammatical, ones (like Determiners and Complementizers). If we take membership in an open vs. closed class of items as a diagnostic distinguishing lexical from functional elements, then the candidates for the functional lexicon of languages become very numerous. Not only Determiners and Complementizers are functional, but also conjunctions, (functional) adpositions like of, for, from, at, to, with (as well as spatial adpositions - see Cinque and Rizzi to appear, and references cited there), mood, modal, tense, aspect, polarity, and voice morphemes ${ }^{7}$, auxiliaries, copulas and other verbs lacking a clear argument structure, (strong, weak, and clitic) pronouns, demonstratives, quantifiers, numerals (see Kayne 2005,13), classifiers, number (plural, dual, etc.) morphemes, gender or class morphemes, diminutive/augmentative morphemes, degree words, indefinite/whwords, Case morphemes, focusing adverbs (like 'only' and 'also'), comparative and superlative morphemes, and many many more (see Kayne 2005, section 2.1). To judge from Heine and Kuteva's (2002) four hundred, or so, independent grammaticalization targets, the number of functional elements must at least be of that order of magnitude. It is in fact quicker to consider which elements are lexical (belong to an open class). Nouns in all languages appear to be an open class; perhaps the only genuinely open class, as the considerations that follow may indicate. The situation is certainly far less clear for adjectives, adverbs, and verbs (which are often taken to be lexical, open, classes). In many languages, adjectives constitute a closed, often quite small, class of elements. This is especially clear in those languages, like Yoruba (see Cinque 2006a,5 and references cited there), whose adjectives cannot be used predicatively. In such languages the attributive-only adjectives form a closed (generally small) class; a clear sign of their functional status. For discussion and exemplification, see Dixon (1982,2004), Cinque (2006a,4f, to appear). The fact that they appear to form an open class in other languages may be due to the existence of a parallel predicative class of adjectives (which enlarges the set of adnominal adjectives by adding a reduced relative clause source), as well as to possible productive morphological derivations of adjectives from nouns or verbs (e.g. -al, -ous, -ed, etc. in English).

A similar situation is encountered with adverbs, which also constitute a clear closed class of elements in some languages (see Dixon 1982,40; Schachter 1985,21ff; Stutzman 1997,75; Cinque 1999,213fn79, 2006,9fn.22, and references cited there). Furthermore, the fact that they are coded as rigidly ordered affixes in certain languages while they are coded as independent words in others (also in a fixed order) may suggest that generation in head or specifier position of a dedicated functional projection is an option left open to languages by UG.

\footnotetext{
${ }^{7}$ Whether bound or free. On the (functional) syntactic import of bound morphemes, see the recent discussion in Kayne (2005,11f).
} 
If Hale and Keyser's (1993) idea that most transitive and intransitive verbs are not primitive but result from the incorporation of a noun into a limited class of light/general purpose verbs ('do', 'give', 'take', 'put', 'hit', etc.), then even the class of primitive verbs may turn out to be closed and relatively small. This seems confirmed by the fact that some languages typically fail to incorporate the noun into the light verb so that most 'verbal meanings' are expressed as $\mathrm{V}+\mathrm{N}$ periphrases. This is for example the case of Persian. ${ }^{8}$ The typological literature also reports the case of a number of languages from Australia and New Guinea with closed classes of main verbs (see Dixon 1982,225; Pawley 2006). ${ }^{9}$

\section{Comparative syntax and typology}

Crucial to the cartographic approach is the evidence coming from comparative and, more broadly, typological studies. These alone may help singling out the variety (and the limits) of the functional lexicon of UG. In-depth studies of a single, or of few languages, however deep they may be, fall short of revealing the actual richness of the functional/grammatical structure of UG owing to the often silent character of a certain functional category in a certain language (see Kayne 2005a, 2006). More importantly still, as noted, comparison of many different languages may provide evidence for determining the precise relative order of the different functional projections by combining the partial orders overtly manifested by different languages into what, in principle, should be a unique consistent order/hierarchy, imposed by UG. This presupposes that the order of functional projections is fixed within one language, and, more crucially, across languages; hardly an obvious assumption.

Comparative evidence is also crucial in exposing how certain ordering properties are strictly impossible across languages. Even in cases in which variation is permitted by UG, it is never the case that "anything goes". There are precise limits to the observed cross linguistic variation, a fact which calls for a principled explanation. Consider for example the order of demonstratives, numerals and adjectives with respect to the $\mathrm{N}$ (Greenberg's 1963 Universal 20). Even if variation in their relative ordering is extensive, of the 24 mathematically possible orders of the four elements, only 13 are clearly attested in the languages of the world. Apparently only those orders which are obtainable from a unique base order (Dem Num A N) by moving the N (or NP) leftward to higher functional positions in one of the ways independently admitted by the syntax of natural languages (see Cinque 2005 for discussion).

\footnotetext{
8 "Most verbal constructions in Persian are formed using a light verb such as kardan ('do', 'make'), dâdan ('give'), zadan ('hit', 'strike'). The number of verbs that can be used as light verbs is limited, but these constructions are extremely productive in Persian.” (Megerdoomian n.d.). Also see KarimiDoostan (1997).

${ }^{9}$ Interestingly, the literature on agrammatism reports the fact that even main verbs are impaired. See Miceli, Silveri, Villa and Caramazza (1984) (thanks to Franco Denes for pointing out this article to us; there are also cases of selective impairment of the nominal system with verbs relatively spared (Caramazza \& Shapiro 2004), but these are much rarer than cases of selective V impairment). If main verbs are the morphological merge of a noun plus one of a closed class of 'grammatical' verbs, their conclusion that "agrammatism is a heterogeneous disorder that implicates damage of both lexical and syntactic mechanisms" (p.220) may have to be reassessed, and perhaps reduced to a disorder of (different types of) purely grammatical mechanisms.
} 


\section{Cartography and Minimalism}

The cartographic projects have been developed roughly at the same time as the rise and development of the Minimalist Program (Chomsky 1995 and much subsequent work). There is, at first sight, an inherent tension between the complexity of the cartographic representations and the simplicity of the generative devices that minimalist syntax assumes, somehow reflected in the structural poverty of the representations typically found in the minimalist literature. We believe that there is no contradiction between these two directions of research, and the tension, where real, is the sign of a fruitful division of labor. Minimalism focuses on the elementary mechanisms which are involved in syntactic computations, and claims that they can be reduced to extremely simple combinatorial operations, ultimately external and internal Merge, completed by some kind of search operation (Chomsky's Agree) to identify the candidates of Merge. An impoverished computational mechanism does not imply the generation of an impoverished structure: a very simple recursive operation can give rise to a very rich and complex structure, as a function of the inventory of elements it operates on, and, first and foremost, of its very recursive nature. The very simplified structural representations often assumed in the minimalist literature, expressed by the C-T-v-V system, are sometimes taken literally, as substantive hypotheses on the nature of clausal configurations, but the structure of the arguments rarely implies a literal interpretation, and often is compatible with an interpretation of $\mathrm{C}-\mathrm{T}-\mathrm{v}-\mathrm{V}$ as a shorthand for more complex cartographic structures (a fact explicitly acknowledged, e.g., in Chomsky 2001, fn. 8), with $\mathrm{C}, \mathrm{T}$, and $\mathrm{v}$ taken as "abbreviations" standing for complex zones of the functional structure. The division of labor here is that Minimalism focuses on the generating devices, and cartography focuses on the fine details of the generated structures, two research topics which can be pursued in parallel in a fully consistent manner, and along lines which can fruitfully interact (see Cinque 1999, section 6.2, Rizzi, 2004a, introduction and Belletti 2008, introduction, for relevant discussion).

In fact, cartographic studies are based on general guidelines which are at the heart of the minimalist program. Minimalism has introduced a principled typology of UG principles, which are traced back to only two kinds of broad categories: principles dictated by the needs of the interface systems, determining the proper legibility and usability of the interface representations, and economy/locality principles, constraining the functioning of the computing machine.

The first class includes principles determining the mapping of a hierarchical structure into a linear sequence expressible by the human articulatory system, such as Kayne's (1994) Linear Correspondence Axiom and its variants; and principles ensuring the expressibility of properties required by the human conceptual-intentional systems and by the needs of an efficient communication: properties of argument structure, referential dependencies, scope, and informational packaging in discourse and dialogue. All these aspects play a critical role in cartographic studies. Much work on the reordering of elements generating superficial exceptions to the hierarchical order crucially makes extensive use of remnant movement (e.g. Cinque 1999, Koopman and Szabolcsi 2000, but also much work on the left peripheral positions of $w h$ operators in Romance languages and dialects by Munaro, Obenauer, Poletto, Pollock), a direct offspring of the antisymmetric approach. Work on the cartography of the verbal system (Ramchand 2008) and of prepositions (Svenonius $2008 \mathrm{~b}$ and the contributions collected in Cinque and Rizzi to appear) investigate the syntactic correlates of argument structure in structural approaches to the lexiconsyntax interface inspired by Hale and Keyser's (1993) perspective. Much work on the 
fine structure of the left periphery investigates the syntax of dedicated scope-discourse positions in various languages: Romance (Rizzi 1997, Benincà \& Poletto 2004 and many other contributions in Rizzi 2004a and, on Romance dialects, Manzini and Savoia 2005), Germanic (Grewendorf 2002, Haegeman 2006), West African languages (Aboh 2004, 2007), Creole languages (Durrleman 2007), East Asian languages (Endo 2007, Tsai 2007).

The study of locality/economy is also central to the cartographic endeavor, in that the positional articulation uncovered by cartographic studies offers a sound basis for establishing a principled typology of positions which is required by the analysis of intervention locality: within the Relativized Minimality tradition (Rizzi 1990), an intervener of "the same kind" as the target of movement blocks a movement chain; the typology of positions cannot be established in the traditional terms of the A/A' distinction, too coarse, nor in terms of a featural identity between the target and the intervener (too selective), and seems to require a feature-driven typology of an intermediate level of granularity, which can be directly related to the cartographic structures (Rizzi 2004, Starke 2001, Grillo 2008).

One point in which cartographic studies seem to us to fruitfully implement general simplicity guidelines which are proper of minimalism is the study of the elements of syntactic computations. One useful heuristic principle which has guided much cartographic work is the maxim "one (morphosyntactic) property - one feature - one head". This guideline does not exclude the possibility that featurally complex heads may arise in syntax, but they cannot be "atoms" of the syntactic computations, they can only arise through derivational procedures, namely head movement, which may create a complex conglomerate of features by moving featurally simple heads into other heads (it does not matter here whether head movement literally extracts a head from its projection, or is a kind of phrasal movement "in disguise"). It is this kind of intuition which guided the "unpacking" of the Infl node of early P\&P analyses into its elementary component. Of course, a single surface position may express both the lexical content, tense, mood and subject agreement (as Italian present subjunctive part-a-no "that they leave"), but this is done through movement of the verbal head picking up the various elementary specifications. Similar considerations hold for the unpacking of the $\mathrm{C}$ node, of the determiner system, etc.

The basic intuition that cartographic studies try to validate empirically is that natural language design opts for local simplicity whenever possible: each syntactic head has a simple featural specification and can enter into few simple relations with its associates. Preservation of local simplicity is the effect massively produced by the pervasive presence of movement in natural language syntax. Consider for instance A' movement chains, configurations which transparently arise to associate two kinds of interpretive properties to certain expressions. So, the expression this book must be interpreted as the thematic argument of the verb read, and as the topic of the structure in (3):

(3) This book, I will read tomorrow

Natural languages express this state of affairs by having the element occur twice, once in the thematic position and once in the left peripheral position dedicated to topicality. The assignment of argumental thematic properties is, uncontroversially, a matter of head-dependent relation: the verb assigns a certain thematic role to its immediate dependent. What about a scope-discourse property like topicality? The line pursued by cartographic studies is that scope-discourse properties are assigned to 
elements in a configurationally uniform way, mutatis mutandis: there is a dedicated head, Top, normally occurring in the left periphery of the clause, which activates the interpretive instruction "my specifier is to be interpreted as the topic, and my complement as the comment". Under the copy theory of traces the full representation of (3) is

\section{(4) This book [ Top [I will read $<$ this book $>$ tomorrow ] ] Topic Comment}

with the silent copy in object position notated within angled brackets (on traces as silent copies see Chomsky 1995, Sportiche 2007, a.o.). Each head expresses a single property, we do not have complex heads simultaneously assigning to their dependents the complex of properties "patient of the verb and topic of the clause": natural languages opt for local simplicity, simple featural specifications on heads and local attribution of simple interpretive properties, even though the price to pay is a certain increase of global complexity, a richer functional structure and the multiple occurrence (or "movement") of an element in distinct structural positions. Similar considerations hold for other types of $\mathrm{A}$ ' constructions such as focus, questions, relatives, exclamatives, comparatives, etc.

A brief comment on representations like (4). The postulation of a Top head is immediately supported by the fact that in many languages a Top marker is in fact morphologically realized, i.e. Gungbe yà (Aboh 2004, 2007), Japanese wa (for a particular kind of topic), etc. A partial analogy can be drawn between such leftperipheral markers for scope-discourse semantic properties (topic, focus, Q, etc.) and inherent case for argumental properties (instrumental, locative, benefactive,...): both morphosyntactic entities mark certain interpretive properties of one or the other kind, and both may superficially vary across languages in that they may or may not have a morphophonological realization.

This conception of $A^{\prime}$ configurations implements in a very straightforward way the minimalist guideline according to which movement is a device to express an interface effect, and, more generally, that linguistic computations are driven by the satisfaction of certain expressive needs of the interface systems (Fox 2000, Reinhart 2006). Among the advantages of this way of looking at things is the fact that $A^{\prime}$ movement conforms to the general fact that movement is formally triggered by the featural constitution of a c-commanding head. More importantly, this conception makes possible a very transparent approach to the interface between syntax and semantics-pragmatics: peripheral functional heads can be seen as overt "flags" carrying very transparent instructions to the interface systems on how their immediate dependents are to be interpreted.

An objection which is sometimes raised against this view is that it seems to threaten the thesis of the autonomy of syntax. Granting the historical importance of the autonomy thesis in the process of properly structuring a rigorous and well-defined theory of syntax, we fail to see the force of this objection. First of all, we do not see why this conception should be perceived as more of a threat to the autonomy of syntax then the Theta Criterion, or the Projection Principle, or the theta-related character of inherent case assignment, or any other principle aiming at illustrating the transparency (ultimately, the simplicity) of the mapping between form and interpretation. Secondly, we fail to see any empirical or conceptual advantage in a system of syntactic heads solely using interpretively opaque elements such as Inflection rather than Tense or Aspect, Complementizer rather than Focus, Topic or Q marker, and so 
on. Conceptually, a transparent mapping surely is the null hypothesis, any deviation from which would require clear supporting evidence. Empirically, the transparent view is supported by much overt morphological evidence found across languages. Our own feeling is that the issue of cartography and the autonomy thesis should be looked at in the diametrically opposite perspective. The cartographic studies can be seen as an attempt to "syntacticize" as much as possible the interpretive domains, tracing back interpretive algorithms for such properties as argument structure (Hale and Keyser 1993 and much related work), scope, and informational structure (the "criterial" approach defended in Rizzi 1997 and much related work) to the familiar ingredients uncovered and refined in half a century of formal syntax. To the extent to which these efforts are empirically supported, they may shed light not only on syntax proper, but also on the structure and functioning of the cognitive systems at the interface with the syntactic module.

\section{Hierarchies, Syntax and Semantics}

Cartographic studies have drawn detailed structural maps holding across languages, and have made it plausible that core aspects of the functional structure may be universal. One important question which arises is: where does the hierarchy, and its universal properties, come from? It is hard to imagine that the hierarchy may be an irreducible property of UG, disconnected from any other aspect of human cognition; it is also hard to believe that the hierarchy may be a purely arbitrary "cultural" property, rediscovered by every language learner in the same form, language after language, on the basis of pure inductive learning. So, there must be some principles determining the hierarchical sequence, and guiding the child to "rediscover" it in the course of language acquisition.

In some cases, it is very plausible that certain aspects of the hierarchy (like the relative height, or scope, of the elements that constitute it) depend on independent properties of their semantics, even though precisely what elements make up the hierarchy may simply be the result of the linguistic crystallization of a particular set of cognitive categories among the many more that simply do not find a grammatical encoding in UG. Consider for instance the fact that many languages allow a proliferation of left peripheral topics, while the left-peripheral focus position (if a language uses it at all) appears to be invariably unique. It is plausible that this difference may be derivable from the very interpretive properties of topic and focus (Rizzi 1997). If the leftperipheral focal head assigns the focus interpretation to its specifier, and the presupposition interpretation to its complement,

\section{(5) $\left[\begin{array}{llll}\mathrm{XP} & {[\mathrm{Foc}} & \mathrm{YP}\end{array}\right]$ Focus Presupp.}

then a recursion of (5), e.g. with YP headed by a Foc head, would yield an interpretive clash: YP would be presupposed, but would contain a focal constituent. So, the recursion is barred. On the other hand nothing blocks the recursion of a topic phrase: no interpretive property of the comment excludes that it may in turn have a topiccomment structure. Individual languages may opt for a unique topic position as a matter of parametric choice, e.g., in V-2 languages, but there is no universal prohibition stemming from a plausible interpretive constraint in this case. Another example may be the fact that, in the structure of the IP, the element expressing epistemic modality typically is higher than tense: presumably the modality must be 
evaluated over a complete proposition, including the tense specification. Similar considerations may hold for the universal order epistemic modality $>$ root modality, tense $>$ aspects, etc.

In other cases, aspects of the hierarchy may be determined by syntactic constraints on movement. Consider for instance the fact that in many languages leftperipheral topic and focus can cooccur in the fixed order Topic - Focus (e.g., Hungarian: Kiss 1995). This may be due to the fact that Focus often requires movement of the inflected verb to $\mathrm{C}$ (possibly a property related to the quantificational character of Focus), while Topic does not. In a language requiring inversion with Focus, the order Focus Topic would then be blocked by the impossibility of moving the inflected verb past the Topic head, ultimately a case of the Head Movement Constraint (Travis 1984). The validity of a syntactic account of this sort is supported by the fact that the order Focus Topic seems indeed to be possible in a language like Italian, which does not require verb movement with focus. This strongly supports the view that in this case there is no general scope property enforcing a particular order. Along similar lines, one can observe that if a position has island-creating properties, it must be higher than other positions filled by movement: so, for instance, the Hanging Topic (which has island creating properties) must precede the ordinary topic expressed in Romance by Clitic Left Dislocation (Cinque 1990, Beninca' \& Poletto 2004). On certain connections between the theory of movement and the hierarchy see Abels (2007).

Going back to the constraining effects of semantics, a qualification is needed. Clearly, it is not the case that any imaginable semantic property or distinction can be grammaticalized, expressed by a functional element, a special morphology, a morphosyntactic feature ${ }^{10}$ : there is a fairly restrictive universal set of properties that can be expressed by the functional elements entering into the different hierarchies associated to clauses and phrases. So, syntax is heavily constrained by semantics, but is not totally malleable: on the one hand, it respects purely syntactic constraints (such as locality effects); on the other hand, it is often the case that a syntactic device has a core semantic function, but it often acquires an independent life of its own, as it were, extending its scope well beyond its core semantic function. Consider, for instance, grammatical gender, whose core function is the expression of natural gender, but which gets extended to express an arbitrary classification in the nominal lexicon; the expression of tense, situating the event in time with respect the utterance time, but extending to become an obligatory property of the clausal hierarchy, so that also a tenseless mathematical or logical truth must be expressed via a tensed sentence; the subject - predicate articulation expressing the "aboutness" relation, but becoming a general, obligatory property of clausal structures, which forces the use of expletives if the event is not presented about a particular argument; etc. Syntax is organized to express meaning, but does not dissolve into the mere organization of meaningful units: UG expresses the possible items of the functional lexicon and the way in which they are organized into hierarchies, tailored on the needs of the expression of meanings, but not reducing to them.

\footnotetext{
${ }^{10}$ For example, in the extended projection of a NP, we find evidence for different types of quantifiers, demonstratives, numerals, for functional categories of diminutivazation, numerical approximation, etc., but we never find expressed, it seems, distinctions relating to the magical or non magical character of a number (as opposed to its approximation), nor specialized forms meaning dear-to-me, (dear-to you,) not-dear-to-me-and-you parallel to the universal demonstrative distinctions close-to-me, (close-toyou,) not-close-to-me-and-you. One could easily multiply such theoretically possible, yet non-existing, functional distinctions (also see Cinque 1999,224fn.10, and related text).
} 


\section{References}

Abels, Klaus. 2007. Towards a Restrictive Theory of (Remnant) Movement. CASTL, Tromsø.

Abney, Steven P. 1987. The English noun phrase in its sentential aspect. Ph.D. Dissertation, MIT

Aboh, Enoch. 2004. The Morphosyntax of Complement-Head Sequences. New York: Oxford University Press

Aboh, Enoch. 2007. Information structuring begins with numeration. ACLC, University of Amsterdam.

Asbury,Anna, Jakub Dotlačil,Berit Gehrke, Rick Nouwen, eds., 2008. Syntax and Semantics of Spatial P. Amsterdam: Benjamins

Baker, Mark. 1985. The Mirror Principle and Morphosyntactic Explanation. Linguistic Inquiry 16.373-416

Baker, Mark. 2003. Lexical Categories. Cambridge: Cambridge University Press.

Belletti, Adriana. 1990. Generalized Verb Movement. Turin: Rosenberg and Sellier

Belletti, Adriana. ed., 2004. Structures and Beyond. The Cartography of Syntactic Structures, vol.3, New York: Oxford University Press

Belletti, Adriana. 2008. Structures and Strategies. London: Routledge

Benincà, Paola. 2001. The Position of Topic and Focus in the Left Periphery. In G.Cinque and G.Salvi, eds., Current Studies in Italian Syntax. Essays offered to Lorenzo Renzi. 39-64. Amsterdam: Elsevier North-Holland

Benincà, Paola. 2006. A detailed map of the left periphery of medieval Romance. In R.Zanuttini, H.Campos, E.Herburger and P.Portner, eds., Crosslinguistic research in syntax and semantics: Negation, tense and clausal architecture. 53-86. Washington (D.C.): Georgetown University Press

Benincà, Paola and Cecilia Poletto. 2004. Topic, Focus, and V2. Defining the CP Sublayers. In L.Rizzi, ed., The Structure of CP and IP. The Cartography of Syntactic Structures, vol.2. 52-75. New York: Oxford University Press.

Benincà, Paola and Nicola Munaro, eds., forthcoming. Mapping the Left Periphery. The Cartography of Syntactic Structures, vol.5, New York: Oxford University Press

Bianchi Valentina. 2006. On the syntax of personal arguments. Lingua 116, 20232067.

Bobaljik, J.D. 1999. Adverbs: the hierarchy paradox. Glot International 4: 27-28.

Bobaljik, Jonathan D. and Höskuldur Thráinsson. 1998. Two heads aren't always better than one Syntax 1:37-71

Bocci, Giuliano. 2004. Contrastive Focalisation on Topics and Preverbal Subjects in Italian. Rivista di Grammatica Generativa 29.3-60

Brugè, Laura. 2002. The Position of Demonstratives in the Extended Nominal Projection. In G.Cinque, ed., Functional Structure in DP and IP. The Cartography of Syntactic Structures. Vol.1.15-53. New York: Oxford University Press.

Caramazza, Alfonso and Kevin Shapiro. 2004. Language Categories in the Brain. In Belletti, ed., Structures and Beyond. The Cartography of Syntactic Structures, vol.3. 15-38. New York: Oxford University Press

Cardinaletti, Anna. 2004. Towards a Cartography of Syntactic Positions. In L.Rizzi, ed., The Structure of CP and IP. The Cartography of Syntactic Structures, vol.2. 115-165. New York: Oxford University Press

Carlson, Greg N. 1983. Marking Constituents. In F.Heny and B.Richards, eds., Linguistic Categories: Auxiliaries and Related Puzzles. Vol.1. 69-98. Dordrecht: Reidel 
Chesi, Cristiano. 2005. Phases and cartography in linguistic computation: toward a cognitively motivated computational model of linguistic competence. $\mathrm{PhD}$ Dissertation, University of Siena.

Chomsky, Noam. 1957. Syntactic Structures. The Hague: Mouton

Chomsky, Noam. 1986. Barriers. Cambridge, Mass.: MIT Press

Chomsky, Noam. 1995. The Minimalist Program. Cambridge, Mass.: MIT Press

Chomsky, Noam. 2001. Derivation by Phase. In M.Kenstowicz (ed.) Ken Hale: A Life in Language. 1-52. Cambridge, Mass.: MIT Press

Cinque, Guglielmo. 1990. Types of A-bar Dependencies. Cambridge, Mass.: MIT Press

Cinque, Guglielmo. 1994. On the Evidence for Partial N-movement in the Romance DP. In G.Cinque, J.Koster, J.-Y.Pollock, L.Rizzi and R.Zanuttini (eds.) Paths Towards Universal Grammar. Studies in Honor of Richard S. Kayne. 85-110. Washington (D.C.): Georgetown University Press

Cinque, Guglielmo. 1999. Adverbs and Functional Heads. A Cross-linguistic Perspective. New York: Oxford University Press

Cinque, Guglielmo, ed., 2002. Functional Structure in DP and IP. The Cartography of Syntactic Structures, vol.1, New York: Oxford University Press

Cinque, Guglielmo. 2004. Issues in adverbial syntax. Lingua 114.683-710

Cinque, Guglielmo. 2005. Deriving Greenberg's Universal 20 and its Exceptions. Linguistic Inquiry 36. 315-332

Cinque, Guglielmo. 2006a. Restructuring and Functional Heads. The Cartography of Syntactic Structures, vol.4, New York: Oxford University Press

Cinque, Guglielmo. 2006b. Are all languages 'Numeral Classifier Languages'? Rivista di grammatica generativa 31.119-122

Cinque, Guglielmo. 2008. The Fundamental Left-Right Asymmetry of Natural Languages. In S.Scalise et al., eds., Universals of Language Today. Dordrecht: Springer

(http://dspace-unive.cilea.it/handle/10278/214)

Cinque, Guglielmo. To appear. The Syntax of Adjectives. A Comparative Study.

Cinque, Guglielmo and Luigi Rizzi. To appear. Mapping Spatial PPs. The Cartography of Syntactic Structures, vol.6. New York: Oxford University Press

Cruschina, Silvio. 2006. Informational focus in Sicilian and the left periphery. In M.Frascarelli, ed., Phases of Interpretation. 363-385. Berlin: Mouton de Gruyter

Dixon, Robert M.W. 1982. Where have all the adjectives gone? And other essays in semantics and syntax. Berlin: Mouton Publishers

Dixon, Robert M.W. 2004. Adjective classes in typological perspective. In R.M.W., Dixon, A. Aikhenvald, eds., Adjective Classes: A Cross-linguistic Typology. 1-49. Oxford: Oxford University Press

Durrleman, Stephanie. 2007. The Syntax of Jamaican Creole - A Cartographic Perspective. PhD Dissertation, University of Geneva.

Emonds, J. (1978) “The verbal complex V'-V in French". Linguistic Inquiry, 9:151175.

Endo, Yoshio. 2007. Locality and Information Structure - A Cartographic Approach to Japanese. Amsterdam: Benjamins.

Fox, Danny. 2000. Economy and Semantic Interpretation. Cambridge, Mass.: MIT Press.

Frascarelli, Mara and Roland Hinterhölzl. 2007. Types of Topics in German and Italian. In S. Winkler and K. Schwabe, eds., On Information Structure, Meaning and Form. 87-116. Amsterdam: Benjamins. 
Frascarelli, Mara and Annarita Puglielli. To appear. Focus in the Force-Fin System. Information Structure in Cushitic Languages. In Enoch Aboh, K. Hartmann and M. Zimmermann, eds., Focus Strategies: Evidence from African languages. Berlin: Mouton de Gruyter.

Fukui, Naoki. 1995. Theory of Projection in Syntax. Stanford, CA: CSLI Publications.

Furuya, Kaori. 2008. DP hypothesis for Japanese "bare" noun phrases. University of Pennsylvania Working Papers in Linguistics 14.149-162

Giusti, Giuliana. 2002. The Functional Structure of Noun Phrases. A Bare Phrase Structure Approach. In G.Cinque, ed., Functional Structure in DP and IP. The Cartography of Syntactic Structures, vol.1. 54-90. New York: Oxford University Press

Greenberg, Joseph. 1963. Some universals of grammar with particular reference to the order of meaningful elements. In J.Greenberg, ed., Universals of language. 73-113. Cambridge, Mass.: MIT Press.

Grewendorf, Günther. 2002. Left Dislocation as Movement. In S. Manck \& J. Mittelstaedt, eds., Georgetown University Working Papers in Theoretical Linguistics 31-81

Grillo, Nino. 2008. Generalized Minimality - Syntactic Underspecification in Broca's Aphasia. PhD Dissertation, University of Utrecht, University of Siena. Distributed by LOT

Haegeman, Liliane. 2006. Argument Fronting in English, Romance CILD and Left Periphery. In R.Zanuttini, H.Campos, E.Herburger and P.Portner, eds., Crosslinguistic research in syntax and semantics: Negation, tense and clausal architecture. 27-52. Washington (D.C.): Georgetown University Press

Hale, Kenneth and Jay S. Keyser. 1993. On argument structure and the lexical expression of syntactic relations. In K. L. Hale and S. J. Keyser eds. The View from Building 20: A Festschrift for Sylvain Bromberger. 53-109. Cambridge, Mass.: MIT Press.

Heine, Bernd and Tania Kuteva. 2002. World Lexicon of Grammaticalization. Cambridge: Cambridge University Press

Joos, Martin, ed., 1957. Readings in Linguistics I. New York: American Council of Learned Society

Karimi-Doostan, G. 1997. Light Verb Constructions in Persian and Kurdish. Ph.D.Dissertation, University of Essex.

Kayne, Richard S. 2003. Silent years, silent hours. In L.-O.Delsing, C.Falk, G.Josefsson, and H.Á. Sigurðsson, eds., Grammatik i fokus. Festskrift till Christer Platzack den 18 november 2003. 209-226. Lund: Wallin \& Dalholm

Kayne, Richard S. 2005a. Some notes on comparative syntax, with special reference to English and French. In G.Cinque and R.S.Kayne, eds., The Oxford Handbook of Comparative Syntax. 3-69. New York: Oxford University Press

Kayne, Richard S. 2005b. Movement and Silence. New York: Oxford University Press

Kayne, Richard S. 2006. On Parameters and on Principles of Pronunciation. In H.Broekhuis, N. Corver, R. Huybregts, U. Kleinhenz and J. Koster, eds., Organizing Grammar. Linguistic Studies in Honor of Henk van Riemsdijk. 289299. Berlin: Mouton de Gruyter

Kiss, Katalin, ed., 1995. Discourse-Configurational Languages. New York: Oxford University Press.

Koopman, Hilda and Dominique Sportiche. 1991. The Position of Subjects. Lingua 85.211-258 
Koopman, Hilda and Anna Szabolcsi. 2000. Verbal Complexes. Cambridge, Mass.: MIT Press

LaPolla, Randy and Dory Poa (2002) “On Describing Word Order”, ms., City Univ. of Hong Kong (downloadable fromhttp://personal.cityu.edu.hk/\%7Ectrandy/describingwo.pdf).

Megerdoomian, Karine. n.d. http://crl.nmsu.edu/Research/Projects/shiraz/ling/morph.html

Manzini, M. Rita and Leonardo Savoia. 2005. I dialetti italiani e romanzi. Alessandria: Edizioni dell'Orso

Miceli, Gabriele, M.Caterina Silveri, Giampiero Villa and Alfonso Caramazza. 1984. On the Basis for the Agrammatic's Difficulty in Producing Main Verbs. Cortex 20.207-220.

Mioto, Carlos. 1999. A periferia esquerda no português brasileiro. Ms., Universidade Federal de Santa Catarina, University of Siena.

Nicolis, Marco. 2008. Reinforcers in Italian: DP-internal and Left Peripheral. To appear in Proceedings of CLS 41.

Nilsen, Øystein. 2003. Eliminating positions: syntax and semantics of sentential modification. $\mathrm{PhD}$

dissertation, Utrecht University.

Pawley, Andrew. 2006. Where have all the verbs gone? Remarks on the organisation of languages with small, closed verb classes. Paper presented at the 11th Biennenial Rice University Linguistics Symposium, 16-18 March 2006 (http://www.ruf.rice.edu/ lingsymp/Pawley_paper.pdf).

Pereltsvaig, Asya. 2007. On the Universality of DP: A View from Russian". Studia Linguistica 61.59-94

Poletto, Cecilia. 2000. The Higher Functional Field. Evidence from Northern Italian Dialects. New York: Oxford University Press

Pollock, Jean-Yves. 1989. Verb Movement, Universal Grammar, and the Structure of IP. Linguistic Inquiry 20.365-424

Progovac, Ljiljana. 1998. Determiner Phrase in a language without determiners. Journal of Linguistics 34.165-179

Ramchand, Jillian. 2008. Verb Meaning and the Lexicon: A first Phase Syntax. Cambridge: Cambridge University Press

Reinhart, Tanya. 2005. Interface Strategies - Reference-set Computation. Cambridge, Mass.: MIT Press

Rizzi, Luigi. 1985. Two notes on the linguistic interpretation of Broca's aphasia. In M.-L. Kean, ed., Agrammatism. 153-164. New York: Academic Press.

Rizzi, Luigi. 1990. Relativized Minimality. Cambridge, Mass.: MIT Press.

Rizzi, Luigi. 1997.The Fine Structure of the Left Periphery", in L.Haegeman (ed.) Elements of Grammar. 281-337. Amsterdam: Kluwer

Rizzi, Luigi. 2001. On the position "Int(errogative)" in the left periphery of the clause. In G.Cinque and G.Salvi, eds., Current Studies in Italian Syntax. Essays offered to Lorenzo Renzi. 287-296. Amsterdam: Elsevier North-Holland

Rizzi, Luigi. ed. 2004a. The Structure of CP and IP. The Cartography of Syntactic Structures, vol.2, New York: Oxford University Press

Rizzi, Luigi. 2004b. Locality and Left Periphery. In A.Belletti, ed., Structures and Beyond. The Cartography of Syntactic Structures, vol.3, New York: Oxford University Press

Rizzi, Luigi and Ur Shlonsky. 2007. "Strategies of Subject Extraction", in H.M.Gärtner and U. Sauerland (eds). Interfaces + Recursion = Language? Chomsky's Minimalism and the View from Syntax-Semantics. 115-16. Berlin: Mouton de Gruyter 
Schachter, Paul. 1985. Parts-of-speech Systems. In T.Shopen, ed., Language Typology. A Syntactic Description. Vol.I: Clause Structure. 3-61. Cambridge: Cambridge University Press

Schachter, Paul and Timothy Shopen. 2007. Parts-of-speech Systems. In T.Shopen, ed., Language Typology. A Syntactic Description. Vol. I: Clause Structure. Second Edition. 1-60. Cambridge: Cambridge University Press

Schweikert, Walter. 2005. The Order of Prepositional Phrases in the Structure of the Clause. Amsterdam: Benjamins

Scott, Gary-John. 2002. Stacked Adjectival Modification and the Structure of Nominal Phrases. In G.Cinque, ed., Functional Structure in DP and IP. The Cartography of Syntactic Structures. Vol.1.91-120. New York: Oxford University Press.

Shlonsky, Ur. 1997. Clause Structure and Word Order in Hebrew and Arabic. New York: Oxford University Press

Shlonsky, Ur. 2000. Subject positions and copular constructions. In H.Bennis, M. Everaert and E. Reuland, eds., Interface strategies. 325-347. Amsterdam: Royal Netherlands Academy of Arts and Sciences

Sigurðsson, Halldór Á. 2000. The Locus of Case and Agreement. Working Papers in Scandinavian Syntax 65.65-108.

Sportiche, Dominique. 2007. Division of Labor between Merge and Move: Strict Locality of Selection and Apparent Reconstruction Paradoxes. Ms., UCLA.

Starke, Michal. 2001. Move Dissolves into Merge. PhD Dissertation, University of Geneva.

Stutzman, Verna. 1997. A study of the Lou verb phrase. M.A. Dissertation, University of Manitoba (http://mspace.lib.umanitoba.ca/handle/1993/1324)

Svenonius, Peter. 2008a. The position of adjectives and other phrasal modifiers in the decomposition of DP. In L.McNally and C.Kennedy, eds., Adjectives and Adverbs: Syntax, Semantics, and Discourse. Oxford: Oxford University Press

Svenonius, Peter. 2008b Projections of P. In Asbury,A., J.Dotlačil, B.Gehrke and R.Nouwen, eds., Syntax and Semantics of Spatial P. 63-84. Amsterdam: Benjamins (http://ling.auf.net/lingBuzz/).

Thráinsson, Höskuldur. 1996. On the (non)-universality of functional categories. In W.Abraham, S. D. Epstein, H. Thráinsson and C. J-W. Zwart (eds.), Minimal Ideas: Syntactic Studies in the Minimalist Framework, 253-281. Amsterdam: John Benjamins

Travis, Lisa 1984. Parameters and Effects of Word Order Variation. PhD Dissertation, MIT.

Tsai, Dylan. 2007. Left Periphery and Why-How Alternations. National Tsing-Hua University, Taiwan.

Van Craenenbroeck, Jeroen. 2006. Transitivity failures in the left periphery and footdriven movement operations. Linguistics in the Netherlands 23: 52-64

Zwart, Jan-Wouter. 2006. Uncharted territory? Towards a non-cartographic account of Germanic syntax. Paper presented at the $21^{\text {st }}$ Comparative Germanic Syntax Workshop held at Santa Cruz. To appear in the Proceedings to be published by John Benjamins (http://www.let.rug.nl/ Zwart/docs/cgsw21proc.pdf). 